\title{
Clinical Next-Generation Sequencing Pipeline provides BRCA Traceback to the Families of Deceased Ovarian Cancer Patients
}

\author{
J McGee, E Aref-eshgi, J Kerkhof, A Stuart, P Ainsworth, H Lin, M Volodarsky, CM \\ McLachlin, B Sadikovic
}

\author{
London Health Sciences Centre, Western University, London, Ontario, Canada \\ jacob.mcgee@Ihsc.on.ca
}

Objectives: Advances in Next Generation Sequencing (NGS) allow for multiple gene analysis in an efficient, cost-effective manner. Deceased ovarian cancer patients untested for germline BRCA mutations represent a missed opportunity for clinicians to prevent future cancers in their surviving relatives through Traceback initiatives. We sought to validate our London Health Sciences custom Hereditary Cancer Panel using formalin fixed paraffin embedded (FFPE) tumor samples to assess BRCA $1 / 2$ status in a cohort of deceased high grade serous ovarian cancer (HGSC) patients. In adidtion, we describe the clinical diagnostic yield as determined by the incorporation of CNV and promoter DNA methylation evaluation of BRCA1/2.

Methods: FFPE samples from 172 deceased HGSC patients were assessed using an Illumina MiSeq sequencer with a mean coverage of $1000 x$ and average minimum coverage of $700 x$ when 24 samples were tested per run. The samples were run using a custom-design multi-gene NGS panel containing 37 genes, of which only BRCA1 and BRCA2 were evaluated. Validation of a subset of identified variants was then undertaken using Sanger and Multiplex Ligation-dependent Probe Amplication (MLPA). Extracted genomic DNA were sorted into 3 groups based upon genomic profile size. DNA methylation analysis covered 860,000 human genomic methylation CpG sites. Methylation levels at the promoters of $B R C A 1 / 2$ were examined for a gain of methylation among samples negative for BRCA mutations.

Figure 1: DNA methylation of BRCA 1 promoter

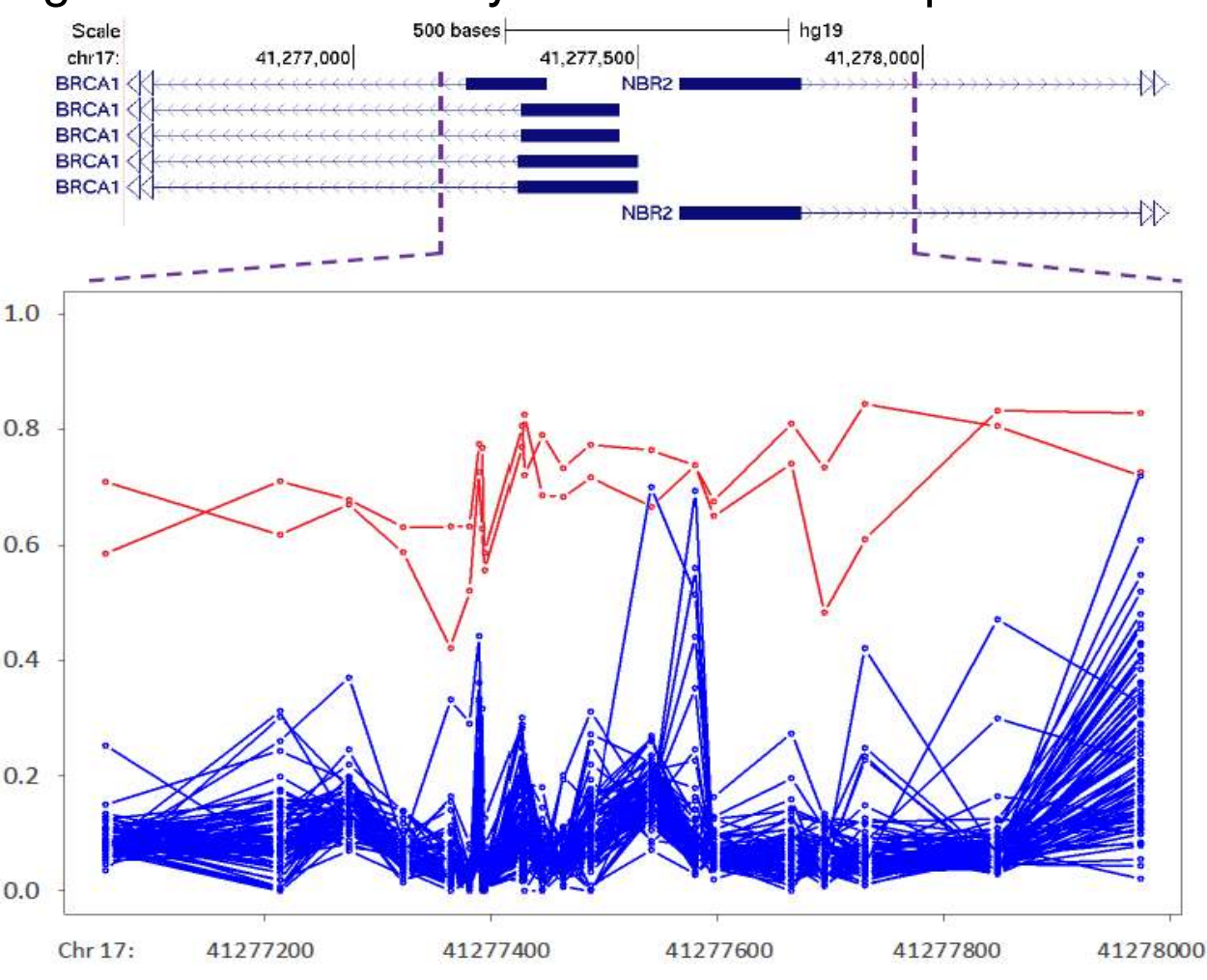

The figure illustrates $>500 \mathrm{bps}$ annotating to the proter of the BRCA1 gene in individuals with no sequence variant findings in $\mathrm{BRCA} 1 / 2$. The methylation levels for each CpG site in this region (0-1) is shown using a circle, connected shown in blue, with two samples showing a gain of methypation (red).
Results: Among 172 HGSC samples, we identified 44 samples (29.3\%) with reportable variants with variant allele frequencies from $10.3 \%-99.4 \%$. The NGS analysis identified 36 samples with at least one reportable variant. Of these, 27 patients had a variant classified as Tier 1 , with 1/27 having both a Tier 1 and a Tier 2 variant and 5/27 having both a Tier 1 and Tier 3 variant. There were 6 samples with only variants of uncertain significance (Table 1). A total of 130 samples were negative for any BRCA $1 / 2$ sequence variants or CNVs, among which 38 were subjected to DNA methylation testing. The methylation analysis of the promoters of BRCA1 and BRCA2 identified 2 additional patients with increased methylation levels of up to $60 \%$ as compared with the rest of the samples, providing a $5 \%$ increase in the diagnostic yield of samples negative in BRCA sequence variant testing (Figure 1).

Conclusion: This NGS pipeline reliably identified BRCA mutations in FFPE tumor samples, allowing for Traceback onto the families of deceased HGSC patients never tested for BRCA mutations. In addition, DNA methylation testing increased the diagnostic yield, and should be incorporated into testing to better identify patients that might benefit from PARP inhibitor treatment.

Table 1 - Reportable sequence variants and CNVs in BRCA 1 and BRCA2 in a subset of patients tested

\begin{tabular}{|c|c|c|c|}
\hline Tier 1 & Tier 2 & VUS & CNVs \\
\hline $\begin{array}{l}\text { BRCA1:C.3254_3255dupGA, } \\
\text { p.(Leu1086Aspfs*2) (57.6\%) }\end{array}$ & & & \\
\hline 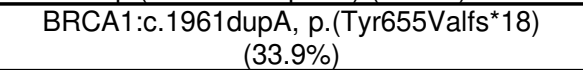 & & & \\
\hline & & & BRCA1x13dup \\
\hline $\begin{array}{l}\text { BRCA1:c.5266dupc, p. (G) n1756Profs"74) } \\
(58.4 \%)\end{array}$ & & & \\
\hline BRCA1:C.5095C >T, p.(Arg1699Trp) $(44.2 \%)$ & & & \\
\hline BRCA1:c.5207T>C, p.(Val1736Ala) (84.7\%) & & & \\
\hline BRCA1:c.4327C>T, p.(Arg1443*) $(46.1 \%)$ & & & \\
\hline BRCA1:c.212+3A>G (96.7\%) & & & \\
\hline $\begin{array}{c}\text { BRCA1:c.5059delG, } p \text {.(Val1687Leufs } 3 \text { ) } \\
(51.3 \%)\end{array}$ & & & \\
\hline & & & BRCA1del \\
\hline $\begin{array}{l}\text { BRCA1:c.5266dupC, p.(Gln1756Profs" } 74) \\
(40.6 \%)\end{array}$ & & & \\
\hline & $\begin{array}{l}\text { BRCA1:c.2891delG, } \\
\left.\text { p.(Gly964Aspfs }{ }^{*} 36\right)(58.4 \%) \\
\text { (Glyos }\end{array}$ & & \\
\hline BRCA1:c.4621G>T, p.(Glu1541*) (31.7\%) & & & \\
\hline BRCA2:c.7615C>T, p. $\left(G \ln 2539^{\star}\right)(11.1 \%)$ & $\begin{array}{l}\text { BRCA1:c.2423_2481del, } \\
\left.\text { p.(Phe808Trpfs }{ }^{\star 3}\right)(27.1 \%)\end{array}$ & & \\
\hline & & & BRCA1del \\
\hline BRCA1:c.1116G>A, p.(TrP372*) (80.1\%) & & & \\
\hline & $\begin{array}{l}\text { BRCA1:c.182G>C, } \\
\text { p.(Cys61Ser) (89.2\%) }\end{array}$ & & \\
\hline BRCA1:c.3967C>T, p. (Gln1323*) (93.3\%) & & $\begin{array}{c}\text { BRCA2:C.9665G>T, } \\
\text { p.(Cys3222Phe) (24\%) }\end{array}$ & \\
\hline $\begin{array}{l}\text { BRCA1:c.5266dupC, p.(Gln1756Profs*74) } \\
(69.3 \%)\end{array}$ & & & \\
\hline & & & BRCA1del \\
\hline & $\begin{array}{l}\text { BRCA1:c.5096G>A, } \\
\text { p.(Arg1699GIn) }(44.6 \%)\end{array}$ & & BRCA2dup \\
\hline & & & BRCA1x13dup \\
\hline $\begin{array}{c}\text { BRCA1:c.68_69delAG, p.(Glu23Valfs*17) } \\
(76.3 \%)\end{array}$ & & & BRCA2duP \\
\hline & $\begin{array}{l}\text { BRCA1:c.3394_3406del, } \\
\text { p.(Asn1132Leufs } 19)(70 \%)\end{array}$ & & BRCA1dup \\
\hline & $\begin{array}{r}\text { BRCA1:C.709G>T, } \\
\text { p. (Glu237* }(51.2 \%) \\
\end{array}$ & & \\
\hline & $\begin{array}{l}\text { BRCA1:c.5074G>A, } \\
\text { p.(Asp1692Asn) (72.8\%) }\end{array}$ & & \\
\hline BRCA2:C.7958T>C, p.(Leu2653Pro) (99.4\%) & & & \\
\hline $\begin{array}{c}\text { BRCA2:C.3170_3174del, p.(Lys1057Thrfs8) } \\
(71.4 \%)\end{array}$ & & & \\
\hline $\begin{array}{l}\text { BRCA2:C.6591_6592delTG, } \\
\text { p.(Glu2198Asnfs*4) (53.7\%) }\end{array}$ & & $\begin{array}{c}\text { BRCA2:C.9305C>T, } \\
\text { p.(Ala3102Val) (43.1\%) }\end{array}$ & \\
\hline $\begin{array}{l}\text { BRCA2:c.7954delG, p.(Val2652Cysfs*5) } \\
(38.5 \%)\end{array}$ & & & \\
\hline BRCA2:C.8167G>C, p.(Asp2723His) $(69.6 \%)$ & & BRCA1:C.-62G>A (57.1\%) & \\
\hline & & & BRCA2del \\
\hline $\begin{array}{c}\text { BRCA2:C.3545_3546delTT, p.(Phe1182*) } \\
(34 \%)\end{array}$ & & & \\
\hline
\end{tabular}

